\title{
Effects of Ankaferd Blood Stopper and calcium alginate in experimental model of hepatic parenchymal bleeding
}

\author{
Aydin $\mathrm{O}^{1}$, Tuncal $\mathrm{S}^{1}$, Kilicoglu $\mathrm{B}^{1}$, Onalan $\mathrm{AK}^{1}$, Gonultas $\mathrm{MA}^{2}$, Ozer $\mathrm{H}^{1}$, Durhan $\mathrm{A}^{1}$, \\ Tasova $\mathrm{V}^{1}$, Hucumenoglu $\mathrm{S}^{2}$, Kismet $\mathrm{K}^{1}$
}

Ankara Training and Research Hospital General Surgery Department, UlucanlarAltindag, Ankara, Turkey. kilicoglubulent@yahoo.com

\begin{abstract}
Background:This experimental study compared the hemostatic effects of calcium alginate and Ankaferd Blood Stopper in hepatic parenchymal bleedings.

Material and method: The study comprised 39 male Wistar albino rats (weight $230 \pm 30 \mathrm{~g}$ ). Laceration model was created in the left lateral lobe of the liver. Standard cotton gauze that was impregnated $0.9 \% \mathrm{NaCl}$ solution and Calcium alginate cover was compared to ABS tampon. The amount of preoperative bleeding, preoperative and postoperative Day 1 hematocrit levels, and the difference between them were assessed and statistically analyzed. Results: Comparing the hematocrit levels between the groups, we found that the amount of bleeding was significantly higher in the control group versus the study groups $(p<0.001)$. Histopathological examination revealed the portal area enlargement and biliary canaliculi proliferation. In the $\mathrm{Ca}^{2+}$ Alginate group, it was observed that the fibres were still present in the incision line with massive fibrotic area around. In the Ankaferd group, examination of the preparations revealed patchy focal necrosis areas but no fibrotic area.

Conclusion: With this study, we demonstrated that both calcium alginate and Ankaferd have hemostatic effect in preventing hepatic parenchymal bleeding and that calcium alginate causes fibrosis in the liver, where ABS causes focal necrosis areas(Tab. 2, Fig. 4, Ref. 19). Text in PDF www.elis.sk. Key words: $\mathrm{Ca}^{2+}$ alginate, ankaferd blood stopper, liver injuries.
\end{abstract}

\section{Introduction}

Liver injuries are of special interest among overall body injuries owing both the incidence and high morbidity and mortality rates. Mortality rate of liver injuries remains high. This rate is increased as the degree of injury is increased or in the presence of additional organ injury (1).

Liver is also the metastasis organ for many tumours. Resection of this metastatic region provides substantial contribution to the survival in many of the malignancies, and in the light of these data, liver resection is being increasingly performed. Bleeding control is the primary problem that the surgeon faces with in such cases or in liver resections performed for any reason (2).

The liver has a very extensive vascular network. This vascularization exists with sinusoidal formation that does not contain smooth muscle fibres, which would provide vasoconstriction. Therefore, uncontrollable severe bleedings occur when tissue integration is impaired in any way (3).

Many methods have been tried to stop hepatic parenchymal bleeding. One of these methods is the use of topical hemostatic

${ }^{1}$ Ankara Training and Research Hospital General Surgery Department, UlucanlarAltindag, Ankara, Turkey, and ${ }^{2}$ Ankara Training and Research Hospital Pathology Department, UlucanlarAltindag, Ankara, Turkey

Address for correspondence: B. Kilicoglu, MD, Ankara Training and Research Hospital General Surgery Department, Altindag, Ulucanlar, Ankara, Turkey.

Phone: +903125953438 agents. For this purpose, studies have been performed with oxidized cellulose compounds, gelatin sponge with or without thrombin, microfiber collagens, and fibrin glue (3).

$\mathrm{Ca}^{2+}$ Alginate cover (Sorbalgon, Hartmann) is a topical hemostatic agent, which acts by releasing $\mathrm{Ca}$ ion and provides clotting. Alginate consists of $\alpha$-L-glucuronic acid and P-D-mannuronic acid monomers, which are derived from algae. Alginate fibres have been largely used in the recent times in manufacturing wound cover. The fact that this material shows hemostatic efficacy by releasing $\mathrm{Ca}$ ion has been demonstrated in the in vitro studies performed using whole blood samples (4).

Ankaferd Blood Stopper (ABS) is a phytogenic topical hemostatic agent that has become clinically available in the recent years. It provides hemostasis independent from blood coagulation factors enabling focal erythrocyte aggregation with encapsulated protein network (5). The components of the extract have specific effects on endothelium, blood cells, angiogenesis, cellular reproduction, vascular dynamics, and intercellular interaction. ABS shows efficacy on both fibrinogen and agglutinating proteins. Blood cells and blood proteins help ABS to provide network configuration in the bleeding area. The number of studies on the clinical and experimental use of ABS in the abdomen and in hepatic surgery is limited. ABS is composed of standardized mixture of Thymus vulgaris, Glycyrrhizaglabra, Vitisvinifera, Alpiniaofficinaruman$\mathrm{d}$ Urticadioica plants. All of these plants are individually effective on the endothelium, blood cells, angiogenesis, cellular reproduction, vascular dynamics and mediators $(6,7)$. 
The aim of this experimental study was to compare the hemostatic effect of $\mathrm{Ca}^{2+}$ Alginate and Ankaferd Blood Stopper on hepatic parenchymal injury created in rat liver.

\section{Material and method}

This study was carried out at Ankara Training and Research Hospital, Experimental Animals Laboratory. The study started after the approval of Ankara Training and Research Hospital Ethics Committee. Thirty male Wistar albino rats at the age of 10 months and with a mean weight of $250 \pm 30$ grams were used.

Each of the experimental animals was famished the night before the surgery. For anesthesia, the rats inhaled ether for 45-60 seconds in a jar containing ether and then the anesthesia was maintained with $75 \mathrm{mg} / \mathrm{kg}$ subcutaneous Ketamine injection.

Preoperative hematocrit vale was measured using the blood sample taken from the tail into a capillary tube. Antisepsis of the abdominal mid-line, where the incision would be performed, was provided with povidone iodine. The peritoneal space was accessed through a $3 \mathrm{~cm}$ vertical midline incision beginning from the inferior aspect of the xiphoid.

Before creating hepatic bleeding model, a translucent cylindrical plastic box was placed under the left liver lobe and all surgical procedure was performed on a $45^{\circ}$ oblique platform. In this way, overall bleeding that occurred during the procedure could be totally collected in the box. Since the left liver lobe is close to the midline in the rats, it is easy to reach through a midline incision. Therefore, bleeding model was created in the left lobe.

Left liver lobe was accessed through the midline incision. Three incisions with $10 \mathrm{~mm}$ length and 1-2 mm depth were made with No.12 scalpel on the diaphragmatic surface of the lobe. A distance of 4-5 $\mathrm{mm}$ was left between each incision.

Experimental animals were divided into three groups:

In the first group (control group, $n=10$ ), the laceration model was covered with a gauze impregnated $0.9 \% \mathrm{NaCl}$ solution, which was left for 10 minutes without compressing to stop bleeding. The gauze was removed out of the abdomen at the end of 10 minutes.

In the second group (study group, $\mathrm{n}=10$ ), the $2 \times 2 \mathrm{~cm} \mathrm{Ca}^{2+} \mathrm{Al}-$ ginate cover (Sorbalgon, Hartmann) was placed on the laceration model. The cover was put on the laceration region without applying mechanical compression and left there.

In the third group (study group, $\mathrm{n}=10$ ), the $2 \times 2 \mathrm{~cm}$ ABS cover was placed on the laceration model for 10 minutes without compression. ABS cover was removed out of the abdomen at the end of 10 minutes.

In all of the groups, there was a waiting time of 10 minutes following the procedure without any intervention. At the end of this period, the blood collected in the box was transferred into the scaled injector and the amount of peroperative bleeding was measured in millimetres. Abdominal midline incision was closed by continuous suturing technique as single-layer using $3 / 0$ propylene suture material.

Again, blood sample was taken from the tails of the rats into the capillary tubes 24 hours after the surgical procedure, and postoperative hematocrit value was measured.
For histopathological examination, samples were taken from the rats of the study groups 7 days after the surgical procedure under general anesthesia.

\section{Results}

Data were analyzed by SPSS for Windows 11.5 package program. Whether the distribution of continuous variables was close to the normal was assessed by the Kolmogorov Smirnov test; whereas the homogeneity of variances was assessed by the Levene test. Descriptive statistics were represented as the mean \pm standard deviation or median (minimum - maximum) for continuous variables.

The significance of the difference between the groups was analyzed by the one-way analysis of variance (One-Way ANOVA) for the mean values and by the Kruskal-Wallis test for the median values. The results of the one-way analysis of variance and the Kruskal-Wallis test were significant, post hoc Tukey HSD or Conover's nonparametric multiple comparison tests were used to identify the conditions that caused the difference. Whether there was a difference between pre-operative and postoperative hematocrit values within the groups was analyzed by the dependent t-test.

The results were considered statistically significant for the $\mathrm{p}<0.05$.

There was no statistically significant difference between the groups in terms of mean preoperative hematocrit values $(\mathrm{p}=0.430)$ (Fig. 1).

As compared to preoperative hematocrit values, statistically significant decrease was observed in the postoperative hematocrit values in Group SF $(\mathrm{p}<0.001)$, Group CA $(\mathrm{p}<0.001)$ and Group ABS $(\mathrm{p}<0.001)$.

Decrease in the postoperative hematocrit values was statistically significantly higher in the Group SF as compared to the Group CA and Group ABS ( $\mathrm{p}<0.001$ ). No statistically significant difference was determined between the Group CA and the Group $\operatorname{ABS}(\mathrm{p}=0.875)$ (Tab. 1).

Tab. 1.Preoperative and postoperative hematocritvalues of the groups.

\begin{tabular}{lccccc}
\hline & Pre-op & Post-op & p-value $^{\mathrm{a}}$ & Change & p-value $^{\mathrm{b}}$ \\
\hline HTC & & & & & $<0.001$ \\
Group SF & $49.2 \pm 2.0$ & $39.6 \pm 1.9$ & $<0.001$ & $-9.6 \pm 1.1^{\text {cd }}$ & \\
Group CA & $50.2 \pm 1.2$ & $45.3 \pm 1.5$ & $<0.001$ & $-4.9 \pm 0.6^{\mathrm{c}}$ & \\
Group ABS & $50.1 \pm 2.2$ & $45.0 \pm 2.5$ & $<0.001$ & $-5.1 \pm 1.0 \mathrm{~d}$ & \\
\hline
\end{tabular}

a-comparison between preoperative and postoperative hematocrit values within the groups, $\mathrm{b}$ - comparison between the groups in terms of changes in the postoperative versus preoperative period,c - difference between Group SF and Group CA is statistically significant $(\mathrm{p}<0.001), \mathrm{d}$-difference between Group SF and Group ABS is statistically significant $(\mathrm{p}<0.001)$

Tab. 2.Amount of bleeding in the groups.

\begin{tabular}{ll}
\hline Groups & Bleeding \\
\hline Group SF & $0.45(0.4-0.6)^{\mathrm{ab}}$ \\
Group CA & $0.27(0.2-04)^{\mathrm{a}}$ \\
Group ABS & $0.27(0.2-04)^{\mathrm{b}}$ \\
p-value & $<0.001$ \\
\hline
\end{tabular}

a - difference between Group SF and Group CA is statistically significant $(\mathrm{p}<0.001)$, b-difference between Group SF and Group ABS is statistically significant $(p<0.001)$ 


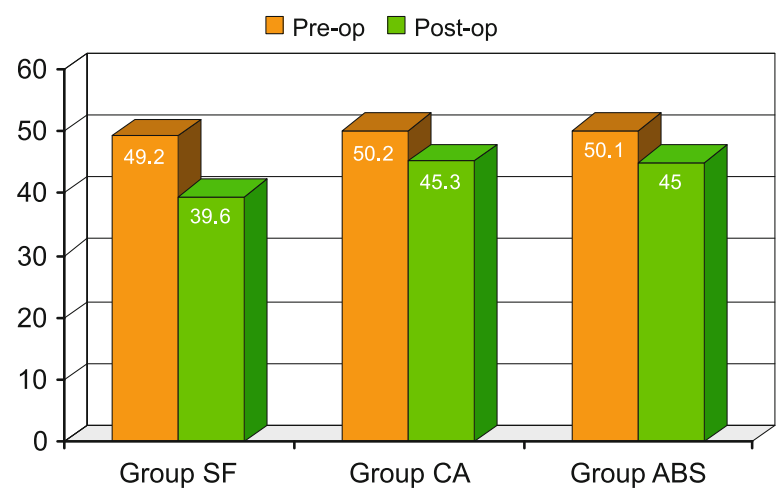

Fig. 1. No statistically significant difference between the groups in terms of mean preoperative hematocrit values.

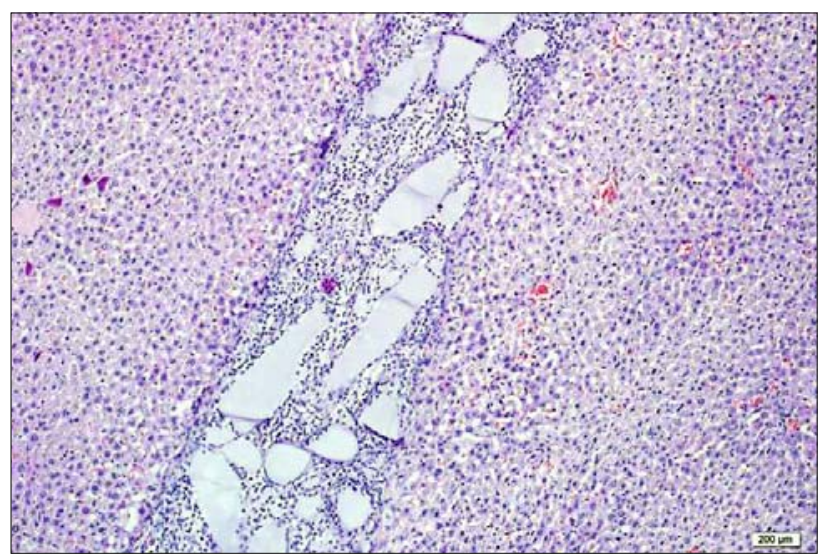

Fig. 2.Ca ${ }^{2+}$ alginate fibres and fibrosis areas.

The amount of bleeding was statistically significantly higher in the Group SF as compared to the Group CA and Group ABS $(p<0.001)$. No statistically significant difference was observed between the Group CA and the Group ABS ( $p=0.706$ ) (Tab. 2).

\section{Histopathological examination}

On the postoperative Day 7, all experimental animals were reopened by a mid-line incision and the lacerated liver region was removed together with a piece of intact liver tissue.

In the $\mathrm{Ca}^{2+}$ Alginate group, it was observed that $\mathrm{Ca}^{2+}$ Alginate fibres remained on the incision line with massive fibrosis area around. The liver tissue out of the incision line appeared to be normal (Fig.2). In the control group (Physiological Serum); portal area enlargement and biliary canaliculi proliferation were observed (Fig.3). In the Ankaferd Blood Stopper group, examination of the preparations revealed patchy focal necrosis areas but no fibrotic area (Fig.4).

\section{Discussion}

Controlling hepatic bleeding with the help of surgical techniques and devices developed in the recent years has significantly reduced the morbidity and mortality in the hepatic surgery. Topi- cal hemostatic agents used to shorten the duration of surgery may provide an advantage for the surgeon. Today, the use of topical hemostatic agents in the hepatic surgery without the standard indication has increased up to $60 \%$ in Japan $(8,9)$. The structure of hemostatic material, severity of bleeding, and emergent or elective surgical approaches, as well as the preference of surgeon, play a role in the selection of these agents. Cost, ease of application, and storage properties of these agents also influence the selection.

The basic mechanism of action in many of the hemostatic agents is that they contact with thrombocytes and activate them and enable the release of hemostatic mediators. Some substances have subsidiary mechanisms of action. For example, fibrin preparations have adhesive cellulose and bovine collagen has plug formation effect (10).

Ankaferd Blood Stopper (ABS) is a phytogenic topical hemostatic agent, which has become clinically available in the recent years. It provides hemostasis independent from blood coagulation factors enabling focal erythrocyte aggregation with encapsulated protein network (6). The substances that constitute the extract have some specific effects on endothelium, blood cells, angiogenesis, cellular reproduction, vascular dynamics, and intercellular interaction. ABS shows its efficacy over both fibrinogen and agglutinating proteins. Blood cells and blood proteins help ABS to provide network formation in the bleeding region (11).

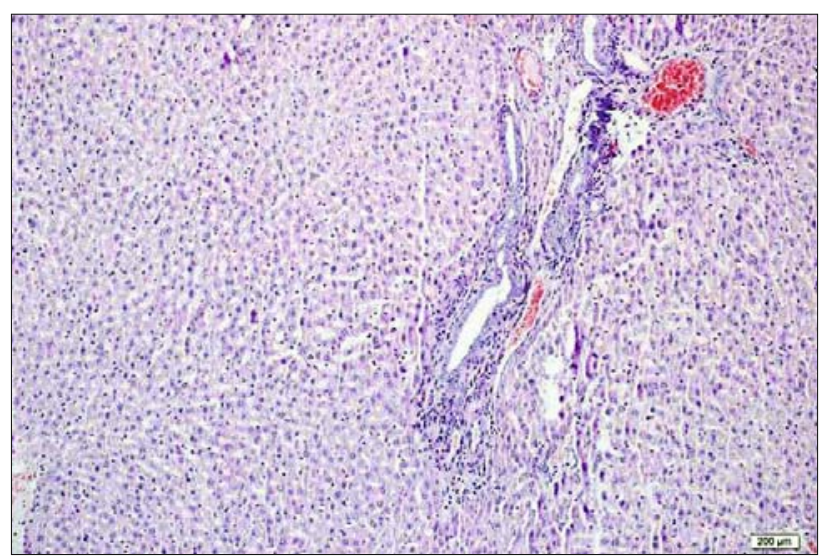

Fig. 3. Portal area enlargement and biliary canaliculi proliferation in Group SF.

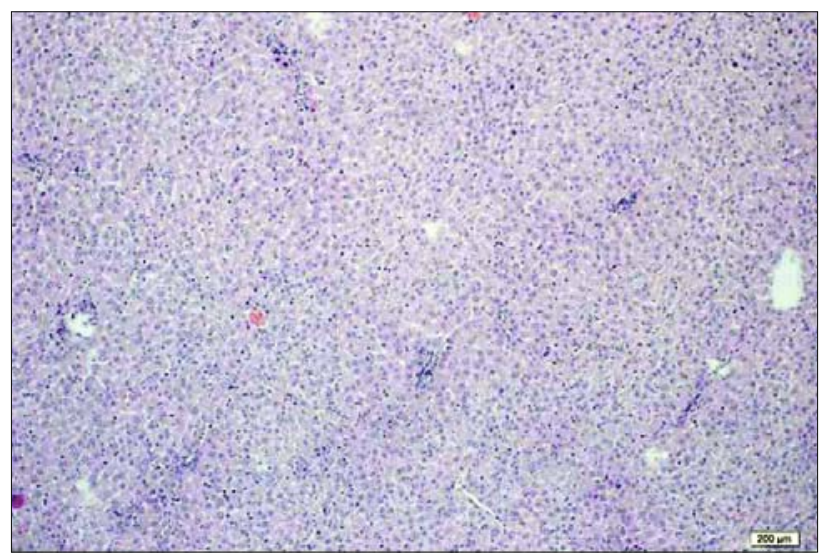

Fig. 4. Focal necrosis areas caused by ABS. 
Kurt et al observed on clinical endoscopic implementations that ABS was effective in the gastrointestinal tract bleeding from hepaticojejunostomy, Dieulafoy lesion and solitary rectal ulcer $(12,13)$. Again, in another study, Karakaya et al exhibited its hemostatic efficacy by comparing suturing material in the rat model of partial liver resection (14). Akarsuet al found that $\mathrm{ABS}$ and fibrin glue have equal topical hemostatic efficacy in the rat model of liver laceration (15).

Alginate is a biodegradable natural polysaccharide, which is composed of a-L-glucuronic acid and P-D-mannuronic acid monomers and is derived from algae. This compound is used as a gelling and stabilizer agent in the food and drug sector. In the recent years, alginate fibres have been largely used in manufacturing wound cover (4). Two alginate molecules combine with a single $\mathrm{Ca}$ ion and form $\mathrm{Ca}^{2+}$ Alginate salt. Alginate has the ion transfer property. $\mathrm{Ca}^{2+}$ ion and $\mathrm{Na}^{+}$ion are replaced by each other when $\mathrm{Ca}^{2+}$ Alginate contacts with the tissue. Thus, $\mathrm{Ca}^{2+}$ ion is carried into the tissue and $\mathrm{Na}+$ ion is carried into the alginate fibres. Combination of fibres with $\mathrm{Na}+$ ion results in gel formation. This property of forming wet gel shows a healing accelerating effect when used as a wound cover. $\mathrm{Ca}^{2+}$ ion that passes into the tissue triggers coagulation by activating thrombocytes, factor VII, IX and X. Positive effect of $\mathrm{Ca}^{2+}$ ion that passes into tissue on aggregation and coagulation has been demonstrated in the studies performed with whole blood samples $(16,17)$.

In the rat model of hepatic laceration, Kinaci et al compared the hemostatic effects of $\mathrm{Ca}^{2+}$ Alginate and standard gauze and observed that hemostatic efficacy of $\mathrm{Ca}^{2+}$ Alginate was superior to gauze and histopathologic examination revealed superficial fibrosis areas in the liver (18). Handerson et al used $\mathrm{Ca}^{2+}$ Alginate as hemostatic material to stop bleeding following tooth extract in children and compared the outcomes with those of standard gauze. In this study, they failed to demonstrate superiority of $\mathrm{Ca}^{2+}$ Alginate to standard gauze in bleeding control (19).

In the present study, considering the amount of postoperative bleeding and hematocrit values, it was observed that hemostatic effects of $\mathrm{ABS}$ and $\mathrm{Ca}^{2+}$ Alginate on the liver were similar. Histopathological examination revealed massive fibrosis on the surfaces where $\mathrm{Ca}^{2+}$ Alginate contacted with the hepatic laceration areas, normal histological appearance in the intact hepatic areas, and adhesion on the other surfaces that $\mathrm{Ca}^{2+}$ Alginate contacted. It was observed that ABS caused focal necrosis areas on the hepatic laceration regions but no fibrosis and adhesion on the other surfaces it contacted.

In conclusion, the present study demonstrated that ABS and $\mathrm{Ca}^{2+}$ Alginate were effective as hemostatic agents in the hepatic parenchymal bleeding and were not superior but close to each other. However, it was observed that ABS caused focal necrosis areas in the liver but $\mathrm{Ca}^{2+}$ Alginate caused fibrosis and adhesion in the organs that it contacted. We think that, new comprehensive studies that would evaluate the long-term adverse events of these two hemostatic agents are needed.

\section{References}

1. Adam R, Chiche L, Aloia T, Elias D et al. Hepatic resection for noncolorectalnonendocrine liver metastases: analysis of 1,452 patients and development of a prognostic model. Ann Surg 2006;244: 524-535.
2. Adam R, Vinet E. Regional treatment of metastasis: surgery of colorectal liver metastases. Ann Oncol 2004;15: 103-106.

3. Chapman WC, Clavien PA,FungJ,KhannaAet al.Effective control of hepatic bleeding with a novel collagen-based composite combined with autologous plasma: results of a randomized controlled trial. Arch Surg 2000;135: 1200-1204.

4. Jarvis PM, Galvin DAJ, Blair SD, McCollum CN. How does calcium alginate achieve haemostasis in surgery? Thrombosis Haemostas 1987;58: 108.

5. Goker H, HaznedarogluIC, Ercetin S, Kirazli S, Akman U, Ozturk Y et al. Haemostatic actions of the folkloric medicinal plant extract Ankaferd Blood Stopper. The Journal of international medical Butenas S, Mann KG. Blood coagulation. Biochemistry (Mosc) 2002;67: 3-12.

6. Matsuda H, Ando S, Kato T, Morikawa T, Yoshikawa M.Inhibitors from the rhizomes of Alpiniaofficinarum on production of nitric oxide in lipopolysaccharide-activated macrophages and the structural requirements of diarylheptanoids for the activity. BioorgMed Chem 2006: 1; 14 (1): 138-142.

7. Oner AF, Dogan M, Kaya A, Sal E, Bektas MS, Yesilmen O et al. New coagulant agent (Ankaferd blood stopper) for open hemorrhages in hemophilia with inhibitor. Clinical and applied thrombosis/hemostasis: official journal of the International Academy of Clinical and Applied Thrombosis/ Hemostasis 2010; 16 (6): 705-707.

8. Cogbill TH, Moore EE,Jurkovich GJ, Feliciano DV, Morris JA,Mucha P. Severe hepatic trauma: a multi-center experience with 1,335 liver injuries. J Trauma 1988; 1433-1438.

9. Nakajima Y,Shimamura T,Kamiyama T, Matsushita M, Sato N, Todo S. Control of intraoperative bleeding during liver resection: analysis of a questionnaire sent to 231 Japanese Hospitals. Surg Today 2002; 32:48-52.

10. Ayşan E, Kinaci E, Başak F et al.Karaciğerparenkimkanamasininengel lenmesindealüminyumsulfatinetkinliği. UlusalCerrahiDergisi 2004; 20:147152.

11. Huri E, HaznedarogluIC, Akgul T, Astarci M, Ustun H, Germiyanoglu C. Biphasic effects of ankaferd blood stopper on renal tubular apoptosis in the rat partial nephrectomy model representing distinct levels of hemorrhage. Saudi Med J 2010; 31 (8): 864-868.

12. Kurt M,Dişibeyaz S,Aldoğan M,Sasmaz N,Aksu S,HaznedaroğluIC. Endoscopic application of ankaferd blood stopper as a novel experimental treatment modality for upper gastrointestinal bleeding: a case report. Am J Gastroenterol 2008; 103: 2156-2158.

13. Kurt M, Kacar S, OnalIK, Akdogan M, HaznedarogluIC.Ankaferd Blood Stopper as an effective adjunctive hemostatic agent for the management of life- threatening arterial bleeding of the digestive tract. Endoscopy 2008; 40 (Suppl 2):262.

14. Karakaya K,Ucan HB,Tascilar O,Emre AU,Cakmak GK,Irkorucu O.Evaluation of a new hemostatic agent Ankaferd Blood Stopper in experimental live laceration. J Invest Surg 2009:22:201-206.

15. AkarsuC, Kalayci MU, Yavuz E, Özkara S, Gökçek B, Özdenkay Y, Yalçin O. UlusalTravmaAcilDerg 2011; 17 (4): 308-312.

16. Yimin Q. Absorption Characteristics of alginate wound dressings. J App Polymer Sci 2004;91(2): 953-957.

17. Thomas S. Alginate dressings in surgery and wound management: Part 2. J Wound Care 2000; 9 (3): 115-119.

18. Kinaci E, Basak F, Dincel O. Efficacy of Calcium Alginate in Prevention of Hepatic Parenchymal Bleeding: An Experimental Study. J GastroenterolHepatol Res 2013;2(5):593-596.

19. Henderson NJ, CrawfordPJ, Reeves BC. A randomised trial of calcium alginate swabs to control blood loss in 3-5-year-old children. Br Dent J 1998;184: 187-190.

Received November 6, 2013. Accepted November 22, 2013 